\section{Leptina: o Diálogo entre Adipócitos e \\ Neurônios}

RESUMO

A descoberta da leptina trouxe consigo um interesse renovado sobre o estudo do controle homeostático da energia. Sabe-se agora que o tecido adiposo branco é o maior sítio de produção da leptina. Uma vez na circulação sangüínea ela se liga a receptores específicos no cérebro, levando ao sistema nervoso central um sinal de saciedade que reflete a quantidade existente de energia em forma de gordura no organismo. Agindo por intermédio de receptores que fazem uso da via JAK/SAT de transdução do sinal intracelular, a leptina modifica a expressão e a atividade de inúmeros peptideos hipotalâmicos que regulam o apetite e o gasto de energia. Além disso, a leptina sinaliza o estado nutricional do organismo a outros sistemas fisiológicos, modulando a função de várias glândulas alvo. Mais recentemente, a leptina recombinante foi administrada com sucesso numa paciente obesa com deficiência do hormônio devido a uma mutação do gene ob. Por outro lado, os efeitos da leptina recombinante no único estudo em pacientes com obesidade e concentrações elevadas de leptina foram menos impressionantes. Nesta revisão, discutiremos a complexidade das ações da leptina com ênfase no seu papel integrativo de sinalizadora do estado nutricional para o organismo. (Arq Bras Endocrinol Metab 2000;44/3: 205-14)

Unitermos: Gene ob; Tecido adiposo; Hipotálamo; Balanço energético: Obesidade.

\begin{abstract}
The discovery of leptin led to a renewed interest in the study of enegy homeostasis. It is now recognized that white adipose tissue is the major site of leptin synthesis. After it is secreted into the bloodstream leptin binds itself to specific receptors in the brain, providing the central nervous system with a satiety signal that reflects the amount of energy stored as fat. Acting through receptors that transduce a signal by the JAK/STAT pathway, leptin modifies the expression and activity of hypothalamic peptides that regulate appetite and energy expenditure. In addition, leptin signals nutritional status to other physiological systems and modulates the function of several target glands. More recently, recombinant leptin was successfully given to an obese patient with leptin deficiency due to a mutation in the ob gene. On the other hand, the effects of recombinant leptin in the only study with obese patients and increased levels of circulating leptin were less impressive. Here we review the complexity of leptin actions with a focus on its integrative role as a signal of nutritional status for the organism. (Arq Bras Endocrinol Metab 2000;44/3: 205-14)
\end{abstract}

Keywords: ob Gene; Adipose tissue; Hypothalamus; Energy balance; Obesity. revisão

\author{
André B. Negrão \\ Julio Licinio
}

Clinical Neuroendocrinology Branch, NIMH, NIH, Bethesda, USA (ABN); UCLA, Department of Psychiatry and Biobehavioral Sciences, Gonda Neuroscience and Genetics Research Center, Los Angeles, USA (JL) 
$\mathrm{O}$ TERMO LEPTINA APARECEU em 3.500 artigos de revistas indexadas desde a sua descoberta até a presente revisão. Um artigo isolado, no qual é descrita a identificação do gene da leptina, já foi citado mais de 2.070 vezes (1). Esses números atestam o quanto avançaram as áreas de investigação ao redor deste novo hormônio. Os trabalhos iniciais sobre leptina versavam sobre seus efeitos biológicos mais evidentes: diminuição do peso e da ingestão alimentar (2). Posteriormente, descobriu-se que a leptina atuava em sistemas fisiológicos independentes do controle de energia (3). Recentemente, ensaios clínicos com leptina recombinante fecharam um ciclo de investigações que começaram com modelos animais de obesidade e chegaram até o tratamento da obesidade em humanos $(4,5)$. Nesta revisão daremos ênfase a dois papéis fundamentais que esta fascinante molécula desempenha no organismo (figura 1).

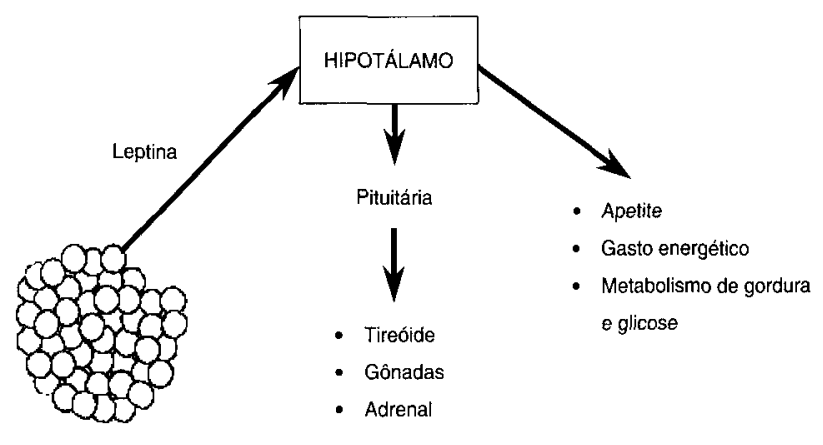

Tecido adiposo

Figura 1 - Diagrama representando o tecido adiposo, o acesso da leptina ao hipotálamo e seus efeitos na regulação de energia e atividade neuroendócrina.

Num primeiro plano, a leptina é um componente integral do complexo sistema fisiológico que regula o armazenamento, o equilíbrio e o uso de energia pelo organismo. Além deste papel, a leptina sinaliza e modula o estado nutricional do organismo para outros sistemas fisiológicos. Este segundo aspecto é evidente diante dos seus efeitos inibitórios sobre o conjunto de alterações neuroendócrinas secundárias à privação alimentar (6). Outro papel da leptina que vai além da sua atividade na regulação do peso corporal é a possibilidade dela ser o sinal bioquímico que informa o cérebro que as reservas energéticas são suficientes para sustentar o início da puberdade e a reprodução (7).

\section{HISTÓRICO}

A descoberta da leptina se deu no contexto das investigações feitas com modelos experimentais de obesidade. Camundongos pertencentes às cepas $a b / o b \mathrm{e}$ $d b / d b$ são três vezes mais pesados do que as cepas selvagens (8). Numa séria de estudos de parabiose entre estas duas cepas de camundongos, ficou claro que a cepa $o b / o b$ era incapaz de produzir um fator circulante presente no tecido adiposo da cepa $d b / d b$. O achado mais interessante destes estudos foi a constatação de que a cepa $o b / o b$ perdia peso quando em contato com o sangue da cepa $d b / d b$, demonstrando que seu cérebro respondia a este fator $(9)$.

Passaram-se duas décadas até que em 1994 o grupo liderado pelo Dr. Friedman da Rockefeller University clonasse o gene deste fator, denominado proteína $o b$ ou leptina (do grego leptos, i.e. magro) (1). Existe uma homologia de $84 \%$ entre o gene da leptina humana e o gene encontrado em camundongos (1). Logo a seguir, passou-se a produzir a leptina recombinante e demonstrou-se que a leptina administrada em camundongos da cepa $o b / o b$ levava a uma perda de peso e reduzia a ingestão calórica (10).

\section{PRODUÇÃO E MECANISMOS REGULATÓRIOS}

O tecido adiposo branco é responsável pela maior parte da leptina produzida pelo organismo. Outros orgãos produzem leptina em menor quantidade: estômago, placenta e tecido adiposo marrom (11-13). A expressão do ácido ribonucléico mensageiro (mRNA) para a leptina é menor em tecido gorduroso visceral do que em tecido subcutâneo em humanos (14). Tal diversidade de sítios de produção é intrigante na medida em que a leptina é secretada em pulsos ao longo do dia, como demonstrado em nossos estudos com voluntários sadios (15). O padrão pulsátil e o período de secreção da leptina sugerem que deva existir um mecanismo coordenador da sua produção nestes diferentes sítios onde a proteína é expressa. O pico de secreção da leptina se dá durante a noite em humanos e as concentrações plasmáticas são pouco influenciadas pelas refeições (15).

A massa total de tecido adiposo do organismo é o fator que mais está associado às concentrações de leptina no sangue. Por extensão, medidas indiretas de gordura corpórea (p.ex. índice de massa corpórea) também estão fortemente relacionadas com a leptina circulante (I6). Porém, diversos mecanismos fisiológicos influenciam a síntese aguda da leptina e conseqüentemente, levam a oscilações nas quantidades de leptina intrinsecamente associadas com a massa de gordura. Jejum, exer- 
cício físico moderado e frio resultam numa diminuição da expressão do gene da leptina e eventual queda nas concentrações plasmáticas da proteína $(17,18)$. Alimentação após jejum, glicocorticóides e insulina são fatores que estimulam a transcrição do gene e a produção de leptina (19-21). Por outro lado, a ativação do sistema nervoso simpático (SNS) por intermédio dos adreno-receptores $3-3 \mathrm{em}$ modelos animais leva a uma diminuição da expressão do gene da leptina (22). Devido a seu controle sobre a lipólise no tecido adiposo branco é razoável supor que a ativação do SNS tenha uma participação primordial na queda das concentrações de leptina durante o jejum.

\section{RECEPTOR E MECANISMO DE AÇÃO}

Há cinco variedades ("splice variants") de receptores da leptina (Ob-Ra/e), porém somente o receptor $\mathrm{Ob}-\mathrm{Rb}$ (forma longa) contém um domínio intracelular que é capaz de transmitir o sinal de ligação com a leptina para dentro da célula (23). O receptor Ob-Rb faz parte da família de receptores das citoquinas, ativando o sistema JAK/STAT de transdução do sinal após sua ligação com a leptina (24). A forma longa do receptor foi encontrada nos mais diversos órgãos incluindo pâncreas, rim, medula adrenal, placenta, ovários e tecido adiposo (25-27). Uma forte presença da expressão do gene do receptor Ob-Rb é vista nos diversos núcleos hipotalâmicos que regulam a ingestão alimentar e o controle do gasto energético (28). Técnicas de imunohistoquímica localizaram a proteína do receptor também no hipotálamo (29). Além disso, leptina injetada dentro dos ventrículos cerebrais levou à expressão do fator de transcrição STAT3 e ativação neuronal em núcleos do hipotálamo (30). Estas evidências dão crédito à idéia de que os efeitos da leptina sobre o balanço energético são mediados por neurônios desta região. Ainda não está claro qual o mecanismo de transporte da leptina para dentro do sistema nervoso central (SNC). Uma vez que a variedade Ob-Ra do receptor é encontrada no endotélio capilar de roedores e de humanos ela pode exercer o papel de transportador ativo da leptina para dentro do cérebro (31). Cabe aqui ressaltar que a obesidade da cepa de camundongos $d b / d b$ é causada por uma mutação no gene do receptor $\mathrm{Ob}-\mathrm{Rb}(32)$. Estes animais produzem leptina, porém são incapazes de transmitir o sinal de ligação por conta do receptor defeituoso. A mutação na cepa $d b / d b$ encontra-se presente também em humanos e está associada à obesidade mórbida nestes indivíduos (33).

\section{CONTROLE ENERGÉTICO}

\section{Sinal Aferente}

Seguramente, uma das funções mais claras da leptina é ser uma aferência para o SNC dentro de uma alça de retroalimentação negativa que regula a massa de tecido adiposo. Ou seja, a leptina informa o cérebro que os estoques de energia em forma de gordura estão adequados. São várias as evidências citadas acima que corroboram tal função. Uma vez produzida no tecido adiposo, a leptina entra na circulação sangüínea e é transportada ligada provavelmente ao seu receptor solúvel (Ob-Re) para os órgãos alvo. Sabe-se ainda que oscilações do peso corporal acarretam mudanças nas concentrações plasmáticas de leptina. Mais do que isso, modelos animais de obesidade induzida por dieta e a maioria dos pacientes com obesidade têm leptina plasmática elevada (34). A administração exógena de leptina em roedores e pacientes com obesidade leva a uma perda de peso às custas da diminuição exclusiva de tecido adiposo $(5,32)$. Finalmente, o efeito das refeições normais tem pouco impacto sobre seu nível sérico, sugerindo que sua atividade no controle energético e saciedade se dêem mais a médio ou longo prazo.

\section{Hipotálamo}

Como visto antes, o hipotálamo parece mediar os efeitos da leptina circulante sobre o peso $\mathrm{c}$ a ingestão alimentar. Mais especificamente, as regiões ventrobasais do hipotálamo (núcleos arqueado, ventro-medial e dorso-medial) contêm as maiores concentrações do receptor $\mathrm{Ob}-\mathrm{Rb}$ em todo o cérebro (35). Além do mais, a expressão da proteína Fos, um marcador da atividade neuronal, encontra-se aumentada nestas mesmas regiões após administração da leptina (36). De fato, estas são as regiões cerebrais classicamente implicadas na regulação do comportamento alimentar em modelos de obesidade por ablação hipotalâmica. Finalmente, as regiões hipotalâmicas densas em receptores de leptina estabelecem comunicação entre si e mandam vias aferentes para o sistema nervoso autonômico e regiōes corticais, fornecendo o substrato anatômico onde se dão as alterações comportamentais e metabólicas causadas pela leptina (37). Naturalmente, a interação da leptina com seu receptor se dá no contexto dos neurônios produtores de neuropeptídeos e neurotransmissores que aumentam (orexígenos) ou diminuem (anorexígenos) a ingestão alimentar (tabelal). Particularmente, a leptina age de modo conspícuo em quatro peptídeos produzidos em neurônios do núcleo arqueado: o neuropeptídeo Y (NPY), o peptídeo relacionado à cepa agouti (AGRP), a pró-opiomelanocor- 
Tabela 1 - Moduladores hipotalâmicos do apetite.

\begin{tabular}{cc}
\hline Diminuição & Aumento \\
\hline Leptina & NPY \\
POMC & AGRP \\
CART & MCH \\
CRH/Urocortina & Orexinas \\
$\alpha$-MSH & Noradrenalina \\
Serotonina & \\
\hline
\end{tabular}

POMC, pro-opiomelanocortina: CART, fator de transcrição cocaína-anfetamina dependente; $\mathrm{CRH}$, hormônio liberador de corticotropina: a-MSH, a-hormônio estimulante do melanócito; NPY, neuropeptídeo Y; AGRP, peptídeo relacionado à cepa agouti; $\mathrm{MCH}$, hormônio concentrador de melanina

ticotropina (POMC) e o fator de transcrição cocaínaanfetamina dependente (CART). Embora seja um modelo incompleto, postula-se que a leptina suprima a atividade dos neurônios que produzem NPY/AGRP (efeito orexígeno) e que ela estimule a atividade de neurônios produtores de POMC ou CART (efeito anorexígeno) (38). A seguir, discutiremos as evidências experimentais que corroboram o modelo de interação da leptina com esses neuropeptídeos.

O NPY estimula o apetite e encontra-se co-localizado com o receptor longo da leptina no núcleo arqueado (39). Do ponto de vista funcional, o jejum causa uma ativação dos neurônios que expressam tanto o mRNA para Ob-Rb como para NPY em ratos (40). No mesmo estudo, a expressão do NPY estava aumentada em camundongos da cepa $o b / o b$, porém as concentrações do neuropeptídeo diminuíram após a administração da leptina. Uma evidência adicional da interação da leptina com o NPY provém de estudos com uma variante da cepa $o b / o b$ sem o gene para o NPY (41). A ausência do NPY atenuou os efeitos da deficiência de leptina uma vez que estes animais são menos pesados e sua ingestão alimentar é menor do que os camundongos $o b / o b$ habituais. Porém, o NPY não age isoladamente no controle de peso. Modelos murinos sem o gene para NPY têm peso normal e respondem à leptina exógena (42). O AGRP é sintetizado no núcleo arqueado apenas nos neurônios que expressam NPY e ele antagoniza os efeitos anorexígenos do hormônio estimulador de melanócitos $(\alpha-\mathrm{MSH})$ sobre os receptores de melanocortina (43). A expressão gênica do NPY bem como a do AGRP são ativadas durante o jejum, levando certos autores a postular que os neurônios que expressam ambos os peptídeos representam uma unidade funcional no núcleo arqueado (38). A queda da leptina ao final de um período de jejum levaria a um aumento da ingestão alimentar gerada pela estimulação do NPY e o bloqueio do efeito anorexígeno do $\alpha-\mathrm{MSH}$ pelo AGRP (44). Os neurônios produtores da POMC no núcleo arqueado são distintos daqueles que expressam NPY/AGRP e a expressão de mRNA para a POMC coincide com a presença de mRNA para o receptor $\mathrm{Ob}$ $\mathrm{Rb}$ (45). A POMC tem um efeito anorexígeno atuando como precursor do $\alpha-\mathrm{MSH}$. Num estado não estimulado, camundongos $o b / o b$ têm baixas concentrações de mRNA para a POMC. Tal situação foi revertida pela administração de leptina, sugerindo um efeito estimulatório do hormônio sobre a POMC (46). O CART foi descoberto em 1998 e atua como um anorexígeno, sendo que sua expressão gênica no núcleo arqueado diminui durante o jejum e aumenta após a administração de leptina (47).

\section{Metabolismo da Glicose e da Gordura}

A leptina administrada à cepa de camundongos $o b / o b$ corrige a hiperglicemia e a hiperinsulinemia destes animais em doses inferiores às necessárias para redução de peso (48). Isto sugere que a leptina interfere de modo mais direto no metabolismo da glicose do que por um efeito secundário à redução do peso. Kamohara et al. (1997) demonstraram que a leptina administrada a uma cepa selvagem de camundongos acarretou um aumento da utilização da glicose pelo tecido muscular (49). Tal efeito foi obtido tanto por administração da leptina por via intravenosa como por via intracérebroventricular, sugerindo que os efeitos da leptina sobre o metabolismo da glicose se dariam por uma ação no SNC. Postula-se também que a leptina isoladamente esteja associada com a hiperfagia vista em casos descompensados de diabetes tipo 1 (DMI). Isto porque a hiperfagia diabética foi abolida após administração da leptina em modelos murinos de DMl (50). Um dos aspectos que ainda fascina os pesquisadores é saber porque os efeitos da leptina sobre a redução do peso se dão preferencialmente às custas da diminuição exclusiva de tecido adiposo (51). Uma possibilidade é que a leptina promova a oxidação de ácidos graxos e triglicérides possivelmente através de um efeito inibitório sobre a atividade da acetil-CoA carboxilase, uma das enzimas reguladoras da síntese de ácidos graxos (52). Visto em conjunto, os efeitos da leptina sobre o peso e o metabolismo da glicose e dos triglicérides sugerem que ela seja usada no tratamento do DM2.

\section{Obesidade}

Os efeitos da leptina sobre o apetite e o gasto energético sugerem que exista um defeito na atividade do hormônio em pacientes com obesidade (16). Logo cedo ficou claro que a maior parte das pessoas com obesi- 
dade têm níveis séricos de leptina proporcionais à sua massa de tecido adiposo, ou como alguns estudos demonstraram, à quantidade de mRNA para leptina no tecido adiposo $(16,34)$. Ou seja, a maioria das pessoas com obesidade não sofre de uma deficiência de leptina. À semelhança do que se postula para o DM2, passou-se a considerar que a obesidade mais freqüentemente encontrada na população é um estado onde há uma resistência aos efeitos de leptina. Assim, postula-se que um acúmulo excessivo de leptina a curto prazo poderia levar a uma "down-regulation" dos receptores centrais e a um reajuste do seu efeito inibidor sobre o apetite. Desta maneira, uma concentração supra normal de leptina seria necessária para o mesmo efeito inibitório sobre o apetite. Outra possibilidade aventada é a de que haja uma insuficiência do sistema de transporte da leptina para dentro do cérebro porque pacientes obesos têm uma diminuição das concentrações liquóricas de leptina quando comparadas com as concentrações plasmáticas do hormônio (53).

De modo análogo à cepa de camundongos $o b / o b$, existem até o presente momento seis casos de pacientes obesos descritos com uma mutação recessiva no gene da leptina (54-56). Mais recentemente, um destes pacientes teve uma perda de peso mantida durante 12 meses de tratamento com leptina recombinante (4). Segundo os autores do estudo, a perda de peso foi devida a uma diminuição da ingestão alimentar e da perda da massa de gordura. No final de 1999 foi publicado o primeiro estudo clínico da leptina recombinante em pacientes com obesidade e controles de peso normal por um grupo patrocinado pela Amgen Inc. (5). Tanto pacientes com obesidade quanto os controles tiveram uma perda de peso proporcional a doses crescentes de leptina num período de quatro semanas. Os pacientes obesos receberam a droga por um total de 24 semanas e mantiveram, em média, uma perda de peso constante ao longo deste período. Apesar de aguardados com grande expectativa pelo universo científico, bem como pela mídia, os resultados deste estudo inicial merecem ser vistos com cautela. Oito pacientes obesos perderam, em média, $7,1 \mathrm{~kg}$ ao longo das 24 semanas recebendo a dose máxima da droga $(0,30 \mathrm{mg} / \mathrm{kg})$ porém os autores observaram uma considerável variabilidade da resposta entre indivíduos. A perda de peso foi principalmente na forma de massa de gordura conforme observado no paciente com a mutação do gene da leptina. Além da grande variabilidade nas respostas à leptina outra limitação do estudo foi o volume administrado do peptídeo $(8 \mathrm{ml} / \mathrm{dia})$ levando a reações inflamatórias importantes no local da aplicação da droga.

\section{FUNÇÃO NEUROENDÓCRINA}

\section{Mecanismos Adaptativos durante o Jejum Pro- longado}

Além do seu papel na regulação do peso corporal, a leptina parece atuar como um modulador neuroendócrino durante períodos de jejum prolongado. A privação alimentar promove a hiperatividade do eixo hipotálamo-hipófise-adrenal (HHA), a redução da fertilidade, a diminuição do metabolismo basal de repouso, a redução da atividade motora e a queda dos níveis circulantes de hormônios tiroidianos (57). Essas modificações neuroendócrinas têm o valor adaptativo de garantir e prolongar o suprimento energético do organismo até que o alimento volte a ser disponível. Dentro deste contexto, a queda nos valores da leptina plasmática durante o jejum seria vista como o sinal que informaria o cérebro da necessidade de ajustes neurohormonais de modo a garantir um metabolismo mais eficiente. De fato, a deficiência de leptina nos camundongos da cepa $o b / o b$ gera um estado artificial de jejum prolongado nestes animais, promovendo as mesmas modificações neuroendócrinas vistas durante a privação alimentar na cepa selvagem (1). Ahima et al. (1996) demonstraram que a administração de leptina em camundongos selvagens durante privação alimentar atenuou a produção de cortisol e restaurou a atividade dos eixos tiroidiano e gonadal mesmo na ausência de recuperação ponderal (58). Os efeitos da leptina nas respostas neuroendócrinas durante a privação alimentar sugerem que ela pode modular individualmente a função glandular. De fato, Heiman et al. (1997) demonstraram que a leptina é capaz de inibir a liberação do hormônio liberador da corticotrofina $(\mathrm{CRH})$ no hipotálamo perfundido de ratos, fornecendo evidências moleculares de que a leptina atua no eixo HHA (59). Em nossos estudos, homens voluntários normais apresentaram secreção diária de leptina inversamente proporcional à secreção de ACTH e cortisol, sugerindo que a leptina seja um supressor da atividade do eixo HHA (15). Algo semelhante é visto na função tiroidiana. A leptina inibiu a supressão da atividade de hormônio liberador da tireotropina durante privação alimentar em roedores (60). Os efeitos da leptina sobre a função gonadal serão comentados a seguir.

\section{Reprodução}

Diante da grande demanda energética da gravidez e lactação, o organismo suprime a atividade reprodutiva quando as quantidades de gordura corporal são escassas (61). Acredita-se hoje em dia que a leptina tenha o 
papel de informar o cérebro que as reservas energéticas na forma de gordura são suficientes para manter a reprodução (7). O primeiro indício do efeito da leptina neste sentido provém de estudos com camundongos da cepa $o b / o b$. Estes animais são inférteis, porém a leptina reverte a disfunção sexual e os camundongos $o b / o b$ são capazes de procriar quando cruzados com a cepa selvagem (62). Um efeito semelhante é visto em cepas selvagens de camundongos uma vez que a leptina antecipa o início da função reprodutiva nestes animais (63). Vários estudos usam do artificio de diminuir a atividade da leptina para verificar sua ação no eixo reprodutivo. Soro anti-leptina injetado no ventrículo cerebral de ratos levou a uma diminuição dos pulsos do hormônio luteinizante $(\mathrm{LH})$ e interrupção do estro (64). Jejum acompanhado da queda da leptina está associado à redução da atividade secretória do $\mathrm{LH}$ em várias espécies (7). Mais recentemente, um estudo demonstrou que a cepa transgênica de camundongos que expressa leptina exageradamente tem a sua puberdade acelerada (65). Os autores notaram porém o aparecimento de hipogonadismo hipogonadotrófico de início tardio nestes mesmos animais. Tal estudo confirma a importância da leptina na reprodução mas aponta para os possíveis efeitos da hiperleptinemia a longo prazo sobre eixo hipotálamohipófise-gonadal ( $\mathrm{HHG}$ ).

É sabido que a desnutrição em crianças leva a um retardo da puberdade e que o baixo peso em adultos está associado a uma função sexual inadequada (61). Na mesma linha de raciocínio do que foi exposto acima para a reprodução, a leptina parece ter o papel de desencadear o início da puberdade em humanos. Por exemplo, a elevação de testosterona em garotos pré-puberes foi antecedida por picos de secreção de leptina que retornaram a níveis basais uma vez atingida a puberdade (66). Meninas, ao contrário, apresentaram concentrações de leptina que aumentaram progressivamente durante o início da puberdade (67). Finalmente, os indivíduos adultos que carregam a mutação na leptina ou no seu receptor apresentam hipogonadismo hipogonadotrófico, atestando a importância funcional da leptina durante a puberdade $(32,55)$.

A seguir, discutiremos alguns dos mecanismos pelos quais a leptina age no eixo HHG. A leptina em baixas doses induziu a liberação do hormônio liberador de gonadotrofinas (GnRH) em porções incubadas de hipotálamo de ratos, bem como induziu a liberação in vitro do hormônio folículo estimulante (FSH) e do $\mathrm{LH}$ pela hipófise (68). O receptor $\mathrm{Ob}-\mathrm{Rb}$ é expresso na hipófise e nos ovários, o que sugere que
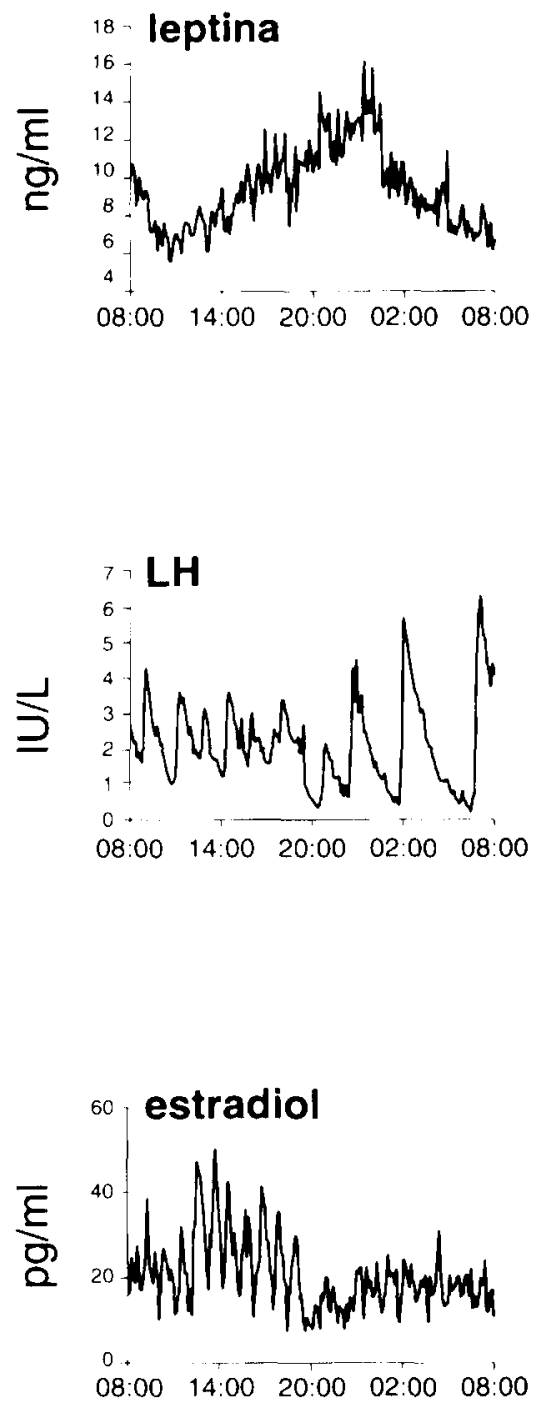

\section{tempo (h)}

Figura 2 - Detalhe dos niveis plasmáticos da leptina, do LH e do estradiol em uma das mulheres. O padrão pulsátil do $\mathrm{LH}$ e as concentrações do estradiol mudam após o pico noturno das concentrações plasmáticas da leptina.

a leptina atue diretamente nestas regiões $(27,69)$. Como visto anteriomente, $\mathrm{Ob}-\mathrm{Rb}$ é encontrado no hipotálamo, uma região implicada no comportamento reprodutivo. Talvez a leptina exerça uma ação indireta sobre os neurônios produtores de $\mathrm{GnRH}$ porque dois estudos não encontraram expressão combinada de mRNA para Ob-Rb e para GnRH nos mesmos neurônios hipotalâmicos $(29,70)$. Com o intuito de observar as influências da leptina no eixo HHG em mulheres na pré-menopausa, nós determinamos as concentrações séricas da leptina, do LH e do estradiol 
em 6 voluntárias de peso normal (71). Amostras de sangue foram colhidas a cada 7 minutos por 24 horas durante o final da fase folicular em cada mulher. Durante o dia, observou-se um padrão no qual baixa amplitude e alta freqüência de $\mathrm{LH}$ era seguido por um padrão noturno de baixa freqüência e alta amplitude do hormônio. A mudança do padrão de liberação do LH coincidiu com o pico noturno de secreção da leptina nestas mulheres (figura 2). A análise dos parâmetros pulsáteis de LH (altura, freqüência, duração dos picos) mostraram diferenças significativas durante o dia, quando os valores de leptina eram baixos, comparados aos valores noturnos, quando os níveis plasmáticos de leptina eram os mais altos. Não encontramós mudanças significativas nos parâmetros pulsáteis do estradiol quando se comparou noite e dia. Foi possível detectar sincronicidade significativa entre a leptina e o LH através da análise de "cross-correlation": os aumentos séricos do LH tendiam a acompanhar decréscimos significativos de leptina num intervalo de 42 a 84 minutos. A “cross-correlation" entre leptina plasmática e estradiol e entre LH plasmático e estradiol não mostrou nenhum intervalo de defasagem significativo ao longo das $24 \mathrm{~h}$. Nós concluímos, a partir deste estudo, que a leptina pode regular as oscilações minuto a minuto do LH e que, o pico noturno de leptina pode determinar o padrão de secreção do $\mathrm{LH}$ no final da fase folicular.

\section{Transtornos Alimentares}

Pacientes com anorexia nervosa são extremamente magras, recusam-se obstinadamente a comer e são amenorréicas (72). Diante deste quadro, vários pesquisadores investigaram a atividade da leptina neste transtorno. Pacientes com anorexia nervosa acompanhadas durante recuperação de peso tiveram a leptina medida no plasma e no líquor (73). As concentrações de leptina nos dois compartimentos foram diretamente relacionados com índice de massa corpórea (IMC). Observou-se nesse estudo que a relação da leptina no líquor e no plasma foi alta nos estágios de recuperação de peso, e mais, pacientes com anorexia nervosa tiveram seus níveis de leptina normalizados antes que seu IMC voltasse ao normal. Os autores postulam que a recuperação precipitada da leptina plasmática pode explicar a resistência a ganho de peso observada em pacientes em tratamento, em particular, nas fases em que os pacientes estão próximos ao peso alvo. Um outro grupo independente também observou que a elevação dos níveis da leptina ocorreu antes da recuperação integral do peso em pacientes com anorexia em fase de tratamento (74). Do ponto de vista repro- dutivo, a leptina de jejum em pacientes com anorexia nervosa é um fator preditivo da volta da menstruação melhor do que IMC, massa de tecido gorduroso ou porcentagem da gordura corporal (75). Nesse mesmo estudo, o nível plasmático mínimo de leptina que prediz a ocorrência da menstruação encontra-se ao redor de $1,85 \mu \mathrm{g} / \mathrm{L}$. Os autores concluem que uma concentração crítica da leptina é necessária para manter a menstruação nestas pacientes.

\section{CONSIDERAÇÕES FINAIS}

As perspectivas do uso da leptina recombinante em humanos devem ser vistas com parcimônia. Por um lado, a visível perda de peso observada no paciente com deficiência congênita da leptina reforça a importância da leptina na regulação do peso e do apetite. Por outro lado, os resultados do estudo clínico em pacientes obesos escolhidos na população geral sugere que existam pessoas com diferentes graus de susceptibilidade aos efeitos da leptina. Seguramente, ainda há muito o que se investigar sobre a complexidade da ação da leptina. Por exemplo, é preciso esclarecer qual a importância dos novos peptídeos que atuam no circuito hipotalâmico que regula o peso sobre a leptina $(76,77)$. Finalmente, a identificação dos fatores de transcrição envolvidos na regulação do gene da leptina poderão ser alvos de drogas que facilitem a sua ação na obesidade (78).

\section{AGRADECIMENTOS}

O Dr. Marc L. Reitman gentilmente nos forneceu o diagrama de tecido adiposo usado neste texto.

\section{REFERÊNCIAS}

1. Zhang Y, Proenca R, Maffei M, Barone M, Leopold L, Friedman JM. Positional cloning of the mouse obese gene and its human homologue. Nature 1994;372:425-32.

2. Campfield LA, Smith FJ, Burn P. The OB protein (leptin) pathway - a link between adipose tissue mass and central neural networks. Horm Metab Res 1996:28:619-32.

3. Mantzoros CS, Moschos SJ. Leptin: in search of role(s) in human physiology and pathophysiology. Clin Endocrinol (Oxf) 1998;49:551-67.

4. Farooqi IS, Jebb SA, Langmack $G$, Lawrence $E$, Cheetham $\mathrm{CH}$, Prentice AM, et al. Effects of recombinant leptin therapy in a child with congenital leptin deficiency. N Engl J Med 1999;341:879-84.

5. Heymsfield SB, Greenberg AS, Fujioka K, Dixon RM, Kushner R, Hunt $\mathrm{T}$, et al. Recombinant leptin for weight loss in obese and lean adults: a randomized, controlled, doseescalation trial. JAMA 1999:282:1568-75. 
6. Flier JS. Clinical review 94: What's in a name? In search of leptin's physiologic role. J Clin Endocrinol Metab 1998:83:1407-13.

7. Cunningham MJ, Clifton DK, Steiner RA. Leptin's actions on the reproductive axis: perspectives and mechanisms. Biol Reprod 1999;60:216-22.

8. Coleman DL, Hummel KP. The influence of genetic background on the expression of the obese $(\mathrm{Ob})$ gene in the mouse. Diabetologia 1973:9:287-93.

9. Coleman DL. Effects of parabiosis of obese with diabetes and normal mice. Diabetologia 1973:9:294-8.

10. Campfield LA, Smith FJ, Guisez Y, Devos R, Burn P. Recombinant mouse $O B$ protein: evidence for a peripheral signal linking adiposity and central neural networks. Science 1995;269:546-9.

11. Bado A, Levasseur S, Attoub S, Kermorgant S, Laigneau JP. Bortoluzzi MN, et al. The stomach is a source of leptin. Nature 1998;394:790-3.

12. Masuzaki H, Ogawa Y, Sagawa N, Hosoda K, Matsumoto T, Mise H, et al. Nonadipose tissue production of leptin: leptin as a novel placenta-derived hormone in humans. Nat Med 1997;3:1029-33.

13. Cinti S, Frederich RC, Zingaretti MC, De Matteis R, Flier JS, Lowell BB. Immunohistochemical localization of leptin and uncoupling protein in white and brown adipose tissue. Endocrinology 1997:738:797-804.

14. Hube F, Lietz U, Igel M, Jensen PB, Tornavist $H$, Joost HG, et al. Difference in leptin mRNA levels between omental and subcutaneous abdominal adipose tissue from obese humans. Horm Metab Res 1996;28:690-3.

15. Licinio J, Mantzoros C, Negrao AB, Cizza G, Wong ML, Bongiorno PB, et al. Human leptin levels are pulsatile and inversely related to pituitary-adrenal function. Nat Med 1997;3:575-9.

16. Considine RV, Sinha MK, Heiman ML, Kriauciunas A, Stephens TW, Nyce MR, et al. Serum immunoreactiveleptin concentrations in normal-weight and obese humans. N Engl J Med 1996;334:292-5.

17. Hickey MS, Houmard JA, Considine RV, Tyndall GL, Midgette JB, Gavigan KE, et al. Gender-dependent effects of exercise training on serum leptin levels in humans. Am J Physiol 1997:272:E562-6.

18. Hardie LJ, Rayner DV, Holmes S, Trayhurn P. Circulating leptin levels are modulated by fasting, cold exposure and insulin administration in lean but not Zucker ( $\mathrm{fa} / \mathrm{fa}$ ) rats as measured by ELISA. Biochem Biophys Res Commun 1996;223:660-5.

19. Trayhurn P. Thomas ME, Duncan JS, Rayner DV. Effects of fasting and refeeding on ob gene expression in white adipose tissue of lean and obese (oblob) mice. FEBS Lett $1995 ; 368: 488-90$

20. De Vos P, Saladin R, Auwerx J, Staels B. Induction of ob gene expression by corticosteroids is accompanied by body weight loss and reduced food intake. J Biol Chem 1995;270: 15958-61.

21. Saladin R, De Vos P, Guerre-Millo M, Leturque A, Girard $J$. Staels $B$, et al. Transient increase in obese gene expression after food intake or insulin administration. Nature 1995:377:527-9.
22. Gettys TW, Harkness PJ, Watson PM. The beta 3-adrenergic receptor inhibits insulin-stimulated leptin secretion from isolated rat adipocytes. Endocrinology $1996 ; 137: 4054-7$.

23. Tartaglia LA, Dembski M, Weng X, Deng N, Culpepper J, Devos $R$, et al. Identification and expression cloning of a leptin receptor, OB-R. Cell 1995;83:1263-71.

24. Touw IP, De Koning JP. Ward AC, Hermans MH. Signaling mechanisms of cytokine receptors and their perturbances in disease. Mol Cell Endocrinol 2000; 160: 1-9.

25. Emilsson V, Liu YL, Cawthorne MA, Morton NM, Davenport $M$. Expression of the functional leptin receptor mRNA in pancreatic islets and direct inhibitory action of leptin on insulin secretion. Diabetes 1997:46:313-6.

26. Hoggard N, Hunter L, Duncan JS, Williams LM, Trayhurn P, Mercer JG. Leptin and leptin receptor mRNA and protein expression in the murine fetus and placenta. Proc Natl Acad Sci U S A 1997:94: 1 1073-8.

27. Karlsson C, Lindell K, Svensson E, Bergh C, Lind P, Billig H, et al. Expression of functional leptin receptors in the human ovary. J Clin Endocrinol Metab 1997;82:4144-8.

28. Mercer JG, Hoggard N, Williams LM, Lawrence CB, Hannah LT, Trayhurn P. Localization of leptin receptor mRNA and the long form splice variant (Ob-Rb) in mouse hypotha amus and adjacent brain regions by in situ hybridization. FEBS Lett 1996:387:113-6.

29. Hakansson ML, Brown H, Ghilardi N, Skoda RC, Meister B. Leptin receptor immunoreactivity in chemically defined target neurons of the hypothalamus. J Neurosci 1998; $78: 559-72$.

30. Vaisse C, Halaas JL, Horvath CM, Darnell JE, Jr., Stoffel M, Friedman JM. Leptin activation of Stat3 in the hypothalamus of wild-type and ob/ob mice but not $d b / d b$ mice. Nat Genet 1996;14:95-7.

31. Banks WA, Kastin AJ, Huang W, Jaspan JB, Maness LM. Leptin enters the brain by a saturable system independent of insulin. Peptides 1996;17:305-11.

32. Lee $G H$, Proenca R, Montez JM, Carroll KM, Darvishzadeh JG, Lee Jl, ef al. Abnormal splicing of the leptin receptor in diabetic mice. Nature 1996;379:632-5.

33. Clement K, Vaisse C, Lahlou N, Cabrol S, Pelloux V, Cassuto $D$, et al. A mutation in the human leptin receptor gene causes obesity and pituitary dysfunction. Nature 1998;392:398-401.

34. Maffei M. Halaas J, Ravussin E, Pratley RE, Lee GH, Zhang $Y$, et al, Leptin levels in human and rodent: measurement of plasma leptin and ob RNA in obese and weightreduced subjects. Nat Med 1995; 1:1 155-61.

35. Schwartz MW, Seeley RJ, Campfield LA, Burn P, Baskin DG. Identification of targets of leptin action in rat hypothalamus. J Clin Invest 1996:98:1101-6.

36. Elmquist JK, Ahima RS, Ellas CF, Flier JS, Saper CB. Leptin activates distinct projections from the dorsomedial and ventromedial hypothalamic nuclei. Proc Natl Acad Sci USA 1998;95:741-6.

37. Canteras NS, Simerly RB, Swanson LW. Organization of projections from the ventromedial nucleus of the hypothalamus: a Phaseolus vulgaris-leucoagglutinin study in the rat. J Comp Neurol 1994;348:41-79. 
38. Schwartz MW, Woods SC, Porte D, Jr., Seeley RJ, Baskin DG. Central nervous system control of food intake. Nature 2000;404:66 1-71.

39. Mercer JG, Hoggard N, Williams LM, Lawrence CB, Hannah LT, Morgan PJ, et al. Coexpression of leptin receptor and preproneuropeptide $Y$ mRNA in arcuate nucleus of mouse hypothalamus. J Neuroendocrinol 1996;8:733-5.

40. Stephens TW, Basinski M, Bristow PK, Bue-Valleskey JM Burgett $S G$, Craft $L$, et al. The role of neuropeptide $Y$ in the antiobesity action of the obese gene product. Nature 1995;377:530-2.

41. Erickson JC, Hollopeter G. Palmiter RD. Attenuation of the obesity syndrome of ob/ob mice by the loss of neuropeptide Y. Science 1996:274: 1704-7.

42. Erickson JC, Ahima RS, Hollopeter G. Flier JS, Palmiter RD. Endocrine function of neuropeptide $Y$ knockout mice. Regul Pept 1997;70;199-202.

43. Hahn TM, Breininger JF, Baskin DG, Schwartz MW. Coexpression of Agrp and NPY in fasting-activated hypothalamic neurons. Nat Neurosci 1998;1:271-2.

44. Mizuno TM, Mobbs CV. Hypothalamic agouti-related protein messenger ribonucleic acid is inhibited by leptin and stimulated by fasting. Endocrinology 1999;140:814 7.

45. Cheung CC, Clifton DK, Steiner RA. Proopiomelanocortin neurons are direct targets for leptin in the hypothalamus. Endocrinology 1997;138:4489-92.

46. Thornton JE, Cheung CC, Clifton DK, Steiner RA. Regulation of hypothalamic proopiomelanocortin mRNA by leptin in ob/ob mice. Endocrinology 1997;138:5063-6.

47. Kristensen P. Judge ME, Thim L, Ribel U, Christjansen KN, Wulff BS, et al. Hypothalamic CART is a new anorectic peptide regulated by leptin. Nature 1998;393:72-6.

48. Schwartz MW, Baskin DG, Bukowski TR, Kuijper JL, Foster $D$. Lasser $G$, et al. Specificity of leptin action on elevated blood glucose levels and hypothalamic neuropeptide $Y$ gene expression in $o b / o b$ mice. Diabetes 1996:45:531-5.

49. Kamohara S, Burcelin R, Halaas JL, Friedman JM, Charron MJ. Acute stimulation of glucose metabolism in mice by leptin treatment. Nature 1997;389:374-7.

50. Sindelar DK, Havel PJ, Seeley RJ, Wilkinson CW, Woods SC, Schwartz MW. Low plasma leptin levels contribute to diabetic hyperphagia in rats. Diabetes 1999:48:1275-80.

51. Halaas JL, Gajiwala KS, Maffei M, Cohen SL, Chait BT, Rabinowitz $D$, et al. Welght-reducing effects of the plasma protein encoded by the obese gene. Science 1995;269:543-6.

52. Bal $Y$, Zhang $S, K i m$ KS, Lee JK, Kim KH. Obese gene expression alters the ability of $30 \mathrm{~A} 5$ preadipocytes to respond to lipogenic hormones, J Biol Chem 1996;271:13939-42.

53. Caro JF, Kolaczynski JW, Nyce MR, Ohannesian JP, Opentanova I, Goldman WH, et al. Decreased cerebrospinalfluid/serum leptin ratio in obesity: a possible mechanism for leptin resistance. Lancet 1996;348:159-61.

54. Montague CT, Farooqi IS, Whitehead JP, Soos MA, Rau $H$, Wareham NJ, et al. Congenital leptin deficiency is associated with severe early-onset obesity in humans. Nature 1997;387:903-8.

55. Strobel A, Issad T, Camoin L, Ozata M, Strosberg AD. A leptin missense mutation associated with hypogonadism and morbid obesity. Nat Genet 1998;18:213-5.

56. Ozata M, Ozdemir IC, Licinio J. Human leptin deficlency caused by a missense mutation: multiple endocrine defects, decreased sympathetic tone, and immune system dysfunction indicate new targets for leptin action, greater central than peripheral resistance to the effects of leptin, and spontaneous correction of leptin-mediated defects. J Clin Endocrinol Metab $1999 ; 84: 3686-95$

57. Schwartz MW, Daliman MF, Woods SC. Hypothalamic response to starvation: implications for the study of wasting disorders. Am J Physiol 1995;269:R949-57.

58. Ahima RS, Prabakaran D, Mantzoros C, Qu D, Lowell B, Maratos-Flier $E$, et al. Role of leptin in the neuroendocrine response to fasting. Nature 1996;382:250-2.

59. Heiman ML, Ahima RS, Craft LS, Schoner B, Stephens TW, Flier JS. Leptin inhibition of the hypothalamic-pituitaryadrenal axis in response to stress. Endocrinology 1997:138:3859-63.

60. Legradi $G$, Emerson CH, Ahima RS, Fller JS, Lechan RM. Leptin prevents fasting-induced suppression of prothyrotropin-releasing hormone messenger ribonucleic acid in neurons of the hypothalamic paraventricular nucleus. Endocrinology 1997:138:2569-76.

61. Frisch RE. The right weight: body fat, menarche and fertility. Proc Nutr Soc 1994:53:113-29.

62. Chehab FF, Lim ME, Lu R. Correction of the sterility defect in homozygous obese female mice by treatment with the human recombinant leptin. Nat Genet $1996 ; 12: 318-20$.

63. Chehab FF, Mounzih K, Lu R, Lim ME. Early onset of reproductive function in normal female mice treated with leptin. Science 1997:275:88-90.

64. Carro E, Pinilla L, Seoane LM, Considine RV, Aguilar E, Casanueva FF, et al. Influence of endogenous leptin tone on the estrous cycle and luteinizing hormone pulsatility in female rats. Neuroendocrinology 1997;66:375-7.

65. Yura S, Ogawa Y, Sagawa N, Masuzaki H, Itoh H, Ebihara $\mathrm{K}$, et al. Accelerated puberty and late-onset hypothalamic hypogonadism in female transgenic skinny mice overexpressing leptin. J Clin Invest 2000; 105:749-55.

66. Mantzoros CS, Flier JS, Rogol AD. A longitudinal assessment of hormonal and physical alterations during normal puberty in boys. $V$. Rising leptin levels may signal the onset of puberty. J Clin Endocrinol Metab 1997;82:1066-70.

67. Clayton PE, Gill MS, Hall CM, Tillmann V, Whatmore AJ, Price DA. Serum leptin through childhood and adolescence. Clin Endocrinol (Oxf) 1997:46:727-33.

68. $\mathrm{Yu}$ WH, Kimura M, Walczewska A, Karanth S, McCann SM. Role of leptin in hypothalamic-pituitary function (published erratum appears in Proc Natl Acad Sci USA 1997 Sep 30:94(20):11108). Proc Natl Acad Sci USA 1997:94:1023-8. 
69. Zamorano PL, Mahesh VB, De Sevilla LM, Chorich LP Bhat GK, Brann DW. Expression and localization of the leptin receptor in endocrine and neuroendocrine tíssues of the rat. Neuroendocrinology 1997:65:223-8.

70. Finn PD, Cunningham MJ, Pau KY, Spies HG, Clifton DK, Steiner RA. The stimulatory effect of leptin on the neuroendocrine reproductive axis of the monkey. Endocrinology 1998; 139:4652-62.

71. Licinio J, Negrão AB, Mantzoros C, Kaklamani V. Wong $\mathrm{ML}$, Bongiorno $\mathrm{PB}$, et al. Synchronicity of frequently sampled, 24-h concentrations of circulating leptin, luteinizing hormone, and estradiol in healthy women. Proc Natl Acad Sci USA 1998;95:2541-6.

72. Negrao $A B$, Cordas TA, Clinical characteristics and course of anorexia nervosa in Latin America, a Brazilian sample. Psychiatry Res 1996;62:17-21.

73. Mantzoros C, Flier JS, Lesem MD, Brewerton TD, Jimerson DC. Cerebrospinal fluid leptin in anorexia nervosa: correlation with nutritional status and potential role in resistance to weight gain. J Clin Endocrinol Metab $1997 ; 82: 1845-51$

74. Hebebrand J, Blum WF, Barth N, Coners $H$, Englaro $P$, Juul $A$, et al. Leptin levels in patients with anorexia nervosa are reduced in the acute stage and elevated upon short-term weight restoration. Mol Psychiatry 1997:2:330-4.
75. Kopp W, Blum WF, von Prittwitz S, Ziegler A, Lubbert $H$ Emons $G$, et al. Low leptin levels predict amenorrhea in underweight and eating disordered females. Mol Psychiatry 1997:2:335-40.

76. Lopez M, Seoane L, Garcia MC, Lago F, Casanueva FF Senaris $R$, et al. Leptin regulation of prepro-orexin and orexin receptor mRNA levels in the hypothalamus. Biochem Biophys Res Commun 2000:269:41-5.

77. Shimada M, Tritos NA, Lowell BB, Flier JS, Maratos-Flier E. Mice lacking melanin-concentrating hormone are hypophagic and lean. Nature 1998;396:670-4.

78. Negrao AB, Licinio J. Obesity: on the eve of a major conceptual revolution. Drug Discov Today 2000:5:177-9.

\section{Endereço para correspondência:}

\section{André B. Negrão}

Clinical Neuroendocrinology Branch

$\mathrm{NIMH}$, DIRP, NIH - Building 10/2D46

10 Center Drive MSC - 1284

Bethesda, MD, 20892-1284, USA

FAX: + 1 (301) 402-1561

e-mail: abnegrao@codon.nih.gov 